\title{
A prática reflexiva e professor em formação
}

Darcísio Natal Muraro ${ }^{1}$

\section{Resumo}

O presente artigo tem por objetivo analisar a concepção de professor reflexivo na filosofia da educação de John Dewey. Indagamos: como Dewey concebe a prática reflexiva e a formação do professor? Para trabalhar esta questão optamos pela metodologia bibliográfica foca na análise do conceito de pensamento reflexivo como busca de solução aos problemas da experiência cotidiana. A prática reflexiva cria hipóteses que antecipam possíveis consequências do agir como prática de liberdade. Pensamento reflexivo constitui um princípio educativo que torna possível a contínua formação do professor. A educação é desenvolvimento do hábito de pensar reflexivo como condição da vida democrática.

Palavras-chave: Dewey; Pensamento reflexivo; Filosofia.

\begin{abstract}
This article aims to analyze the conception of reflective teacher in the philosophy of education of John Dewey. We inquire: how does Dewey conceive the reflective practice and the teacher training? In order to work on this issue we opted for the bibliographic methodology focusing on the analysis of the concept of reflexive thinking as a search for a solution to the problems of everyday experience. Reflective practice creates hypotheses that anticipate the possible consequences of acting as a practice of freedom. Reflective thinking is an educational principle that makes possible the continuous formation of the teacher. Education is the development of the habit of reflective thinking as a condition of democratic life.
\end{abstract}

Keywords: Dewey; Reflective thinking; Philosophy.

${ }^{1}$ Professor Adjunto da Universidade Estadual de Londrina (UEL). 


\section{Introdução}

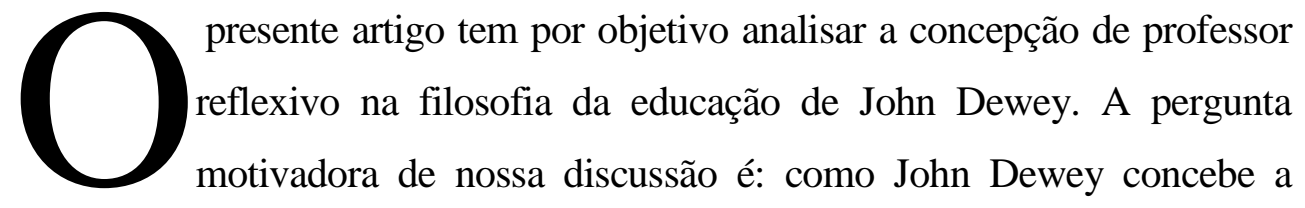
prática reflexiva da qual faz derivar o agir do professor como processo contínuo de formação? O percurso metodológico utilizado é centrado num trabalho bibliográfico de leitura das principais obras do autor e de alguns comentadores que articulam formação de professor com a prática reflexiva buscando compreender conceitualmente esta relação. Considerando que a prática reflexiva é um dos elementos basilares na filosofia deweyana, o trabalho pretende analisar esta concepção e como ela constitui um princípio educativo para uma prática democrática. Busca-se, assim, analisar a prática reflexiva e democrática como um caminho que o autor indica para educar os educadores

Iniciamos nossa pesquisa recorrendo à análise de Zeichner, estudioso da temática educacional em Dewey, especialmente da educação reflexiva, que ressalta a contribuição do autor neste campo:

Histórica e conceitualmente, Dewey nos fornece a fundamentação para nossa compreensão de professor reflexivo. Suas ideias formam uma importante parte de nossa compreensão de ensino reflexivo. Esta noção de mente aberta, responsabilidade, e devotamento de coração são as características chaves do professor reflexivo. (ZEICHNER, 1996, p. 13-14).

Zeichner se propõe a refletir sobre os questionamentos que são dirigidos às concepções deweyanas, que reformulamos aqui da seguinte maneira: seria a proposta de Dewey idealizada e divorciada da complexa e incerta realidade da sala de aula? Como trabalhar com as inúmeras restrições institucionais como a falta de tempo, grande quantidade de alunos, a pressão para dar conta de um amplo currículo?

$\mathrm{Na}$ perspectiva deste estudioso, é possível responder a estes questionamentos tomando por base a defesa que Dewey faz da necessidade 
de balancear os aspectos da rotina e da reflexão: "Para Dewey, é a cegueira de agir sem questionar as verdades recebidas e a arrogância de questionar tudo em todo o tempo." (ZEICHNER, 1996, p. 13). Na mesma linha de argumentação, Zeichner coloca a gravidade do problema das decisões dos professores serem dirigidas por outros, por impulso ou espontâneas ou por convenções sociais sem tomar consciência de que esta decisão seja a certa a ser feita. Portanto, esta postura de assentimento tácito que permeia grande parte da prática docente se contrapõe a uma prática baseada em decisões elaboradas reflexivamente pelo professor. Nesta perspectiva, Zeichner observa que é necessário compreender a radicalidade da proposta de Dewey no que se refere à autonomia do professor diante das interferência dos ditames externos: "Muitos dos que abraçaram as ideias de Dewey sobre os professores como profissionais reflexivos, veem os professores como líderes educacionais que podem aprender com os outros e que tomam direções, mas nunca subserviente aos que estão distantes da sala de aula" (ZEICHNER, 1996, p. 13).

Consideramos importante destacar, neste início de discussão, o trabalho de Anísio Teixeira que foi aluno de Dewey em 1928, e é o pioneiro na recepção das ideias deweyanas no Brasil. Certamente Dewey serviu de inspiração a Teixeira para pensar o problema da educação no Brasil, especialmente na obra Educação não é privilégio. E a crítica deste intelectual soa ainda muito atual: "Toda nossa educação se conservou seletiva e de elite." (TEIXEIRA, 2007, p. 77). Na leitura de Teixeira, a escola brasileira, enredada no dualismo social entre os favorecidos e os desfavorecidos, caracterizou-se como uma escola para os ricos, os privilegiados, em seu programa e currículo, e nunca foi uma escola para todos. Esta escola oferecia uma educação que generaliza os privilégios da sociedade hierarquizada e elitista e, desta forma, excludente da classe popular, pobre. Teixeira tem posição clara quanto à necessidade de romper a educação elitista para os privilegiados ao pensar outro modelo de escola que deveria ser pública, universal, gratuita e eficiente no sentido de promover o aprender a pensar e viver democraticamente: 
Por isso mesmo, não pode ser uma escola de tempo parcial, nem uma escola somente de letras, nem uma escola de iniciação intelectual, mas uma escola sobretudo de prática, de iniciação ao trabalho, de formação de hábitos de pensar, hábitos de fazer, hábitos de trabalhar e hábitos de conviver e participar de uma sociedade democrática, cujo soberano é o próprio cidadão. (TEIXEIRA, 2007, p. 66-67)

Teixeira critica, na primeira parte deste excerto, o programa da escola elitista aos desfavorecidos que acaba por excluí-los, uma vez que somente os privilegiados terão condições de segui-la. Por isso, é necessário repensar a educação popular, destacando-se o papel do professor:

O papel do professor está em despertar os problemas, torná-los sentidos ou conscientes, dar-lhes uma sequência organizada e prover os meios necessários para que os alunos os resolvam, de acordo com o melhor método e os melhores conhecimentos (TEIXEIRA, 2007, p. 71).

As considerações de Zeichner e Teixeira são vozes que motivam o estudo do pensamento deweyano sobre a prática do professor reflexivo pelo impacto das ideias deste pensador para a filosofia e a educação mundial e brasileira em particular.

\section{Filosofia e educação}

Para encaminhar este estudo, partimos do problema que Dewey se coloca que é a necessidade de uma reconstrução da filosofia e da educação diante das mudanças da vida social, da revolução da indústria e do desenvolvimento da ciência e da democracia. Nosso estudo se baseia principalmente nestas duas obras do autor: Reconstrução em filosofia (1959a) e Democracia e educação (1979b). Para Dewey, o projeto de reconstrução da filosofia deveria ser crítico e criativo diante das ideias e ideais que orientam a vida como um acontecimento, uma experiência da qual somos responsáveis pela sua direção. Esta reconstrução deveria ser feita num duplo movimento: por um lado, deveria romper com os dualismos tradicionais das filosofias que separavam o 
pensar da experiência, a inteligência da ação, a teoria da prática, o saber do fazer, o espírito do corpo, o trabalho do lazer, o ensinar do aprender. As teorias filosóficas que sustentam estes dualismos isolam o pensar da experiência criando um mundo superior sustentado pela poderosa razão que se faz voz de uma classe e, assim, justifica da ordem social. O outro movimento da reconstrução da filosofia, rompendo com a perspectiva da razão como contempladora de si mesma, consiste em recolocar a função vital do pensar que é resolver os problemas que os seres humanos enfrentam na sua experiência cotidiana visando uma transformação social. Tal projeto implicava, necessariamente, superar os dualismos filosofia e ciência, filosofia e educação, estabelecendo um diálogo entre estas esferas uma vez que elas colocam os problemas na condução da experiência.

A educação foi se constituindo como uma prática oficial na sociedade ocidental concomitantemente com o desenvolvimento das ciências e do capitalismo. Neste sentido, a educação escolar está fortemente influencia por estes dois vetores. Para sustentar a educação científica, a própria educação deveria ser amparada pela ciência. É interessante observar que, neste contexto amplo de mudanças, a pedagogia passa a ter o caráter de cientificidade, pelo menos desde Herbart (2003). Este pensador defendeu que a pedagogia deve ser guiada pela ciência tendo a psicologia o papel de ditar os meios e a filosofia os fins da educação. Ele compreende a mente humana à moda de Locke como uma folha de papel em branco que deveria ser preenchida por conteúdos. Neste caso, o professor tem autoridade plena no sentido de transmitir os conteúdos que formarão a mente e o caráter da criança. Estavam lançadas as bases para o que se chamou pedagogia tradicional.

Dewey reconheceu os limites da educação tradicional no seu próprio processo formativo na escola que passou. Sua infância foi marcada pelo espírito familiar comunitário no qual as crianças desenvolvem pequenas tarefas como forma de despertar um espírito de responsabilidade. (Cf. Amaral, 1990, p. 32) Sua educação básica e universitária deixou a marca de uma forte divisão: por um lado, a vida escolar marcada pelo fastio e pesadelo da "escola de memorização", dos livros escolares e aulas que não 
despertavam interesse nos alunos; por outro lado, o interesse pelas demais leituras e um rico e amplo aprendizado fora da escola. Dewey fez a crítica a esta educação centrada na memorização pois ela falhava diante da avalanche de problemas complexos colocados pelo contexto histórico norte-americano marcado pela urbanização, industrialização, secularização e universalização da educação. Seria necessário criar uma filosofia e uma educação voltadas para responder aos problemas emergentes. Nesta perspectiva, este contexto contribuiu para o projeto de reconstrução da filosofia e da educação levado adiante por Dewey. A formação do professor reflexivo ganhou destaque nesta reconstrução da teoria filosófico-educacional de Dewey.

Nosso argumento é que a reflexão, conceito basilar na reconstrução da filosofia feita por Dewey, tem sua origem no campo da filosofia e não na ciência, e é condição de possibilidade desta. Se este argumento procede, filosofia e ciência devem trabalhar como aliadas para não serem alienadas. Cabe indagar: qual o papel que Dewey atribui à ciência e à filosofia? Para marcar essa diferença, demos voz ao autor: "Esta direta e íntima conexão da filosofia com uma visão de vida, a diferencia da ciência" (DEWEY, 1979b, p. 357). Para ele, a filosofia é uma atitude total diante da experiência atravessada pelos conflitos, diz ele "[...] por existir a necessidade de integrar na ação os vários interesses em conflito, da vida" (DEWEY, 1979b, p. 359). Ele entende que quando os interesses emergem na experiência de maneira muito superficial, fundindo-se facilmente com acomodações grosseiras ou são insuficientemente organizados de forma a não conflitarem entre si, a filosofia não se faz necessária ou se torna uma "filosofia caseira". A filosofia se faz necessária quando as contraposições ou embates de interesses que influem sobre a vida tais como ciência e religião, economia e ciência / estética; conservadorismo e liberdade; instituição e indivíduo, etc. são motivadores dos problemas para a reflexão e a descoberta de alternativas mais compreensivas que harmonizem os conflitos e restaurem a continuidade da experiência. Quando os ideais de conduta que atingem a toda a sociedade são muito diferentes e discrepantes entre si surge a necessidade da reflexão que resulta nos sistemas filosóficos. "Se existem patentes incertezas na vida, as 
filosofias devem refletir essas incertezas" (DEWEY, 1979b, p. 360). Assim, para Dewey, a filosofia tem papel importante a contribuir no sentido de pensar as dificuldades que surgem da experiência, portanto, pensar os problemas da vida humana em sociedade. Dotado de sensibilidade impar aos problemas sociais, como relatado em sua em sua breve biografia (Dewey, 1930), ele percebeu que a educação era o campo em que estes conflitos deveriam ser tratados de forma filosófica, iniciando uma linha de investigação que chamou de filosofia da educação, delimitada da seguinte forma:

A “filosofia da educação" não é a aplicação exterior das ideias já feitas a um sistema de prática escolar que tivesse origem e meta radicalmente diversas: é apenas uma formulação explícita dos problemas da formação de uma mentalidade reta e de bons hábitos morais, tendo-se em vista as dificuldades da vida social contemporânea. A mais profunda definição de filosofia que se possa dar é a de ser a teoria da educação em seus aspectos mais gerais. (DEWEY, 1979b, p. 364)

Entendemos que a "formulação explícita dos problemas" do campo da educação é uma atividade genuinamente filosófica e com viés ético quando se ocupa com a formação desta "mentalidade reta e bons hábitos morais". Isto nos leva a entender a teoria deweyana do pensamento reflexivo como uma teoria do processo de educar ou de viver de modo democrático sendo eminentemente filosófica.

Um aspecto desta teoria da educação por ele propugnada, e que colocamos como objeto de estudo neste trabalho, é o que dize respeito à formação do professor por meio da experiência reflexiva.

Nossa interpretação do pensamento de Dewey (1979b) destaca o significado que este deu à filosofia como atitude reflexiva caracterizada pela criticidade, totalidade, generalidade, radicalidade e criatividade. Como estas características da atividade reflexiva voltam-se sobre o próprio pensamento, Dewey entende que a filosofia consistiria no "pensamento que se tornou consciente de si mesmo", ocupando seu "lugar, função e valor na experiência" (DEWEY, 1979b, p. 359). O "pensamento consciente de si mesmo" seria a 
metafísica ou filosofias expectadoras do conhecimento. Por isso a ênfase no pensar da, na e para a experiência. Amaral discute o papel da filosofia para Dewey interpretando esta como um esforço de reflexão que eleva os resultados da ciência, estes também como crenças, a graus mais elevados de generalização e, neste sentido, como um "[...] agente do enlace entre as conclusões da ciência e os modos de ação social e pessoal. (AMARAL, 1990, p. 113). A filosofia, na reflexão desta leitora de Dewey é "[...] um método de resolver os problemas do homem em suas relações com as condições reais de vida presente." (AMARAL, 1990, p. 112).

Esta relação entre a filosofia e a educação visa mostrar que a dicotomia entre a teoria e prática nasce da falta de captá-las de forma interativa. O processo de construção e reconstrução dos significados dos problemas e conceitos da experiência se dá através do pensamento reflexivo.

\section{O pensamento reflexivo, educação e formação do professor}

O pensamento reflexivo constitui um princípio educativo e, da mesma forma, um princípio da vida democrática, para Dewey. O método de educar é o mesmo método da democracia é o pensar reflexivo, um bem socialmente em construção que deve ser socializado como forma de conduzir a vida social. A educação se define pelo trabalho que pode fazer para converter o pensar num pensar reflexivo: “[...] é evidente que a educação, quanto a seu lado intelectual, está vitalmente relacionada com o cultivo da atitude do pensar reflexivo, preservando-o onde já existe, e substituindo os métodos de pensar mais livres por outros mais restritos, sempre que possível. (DEWEY, 1979a, p. 85, itálicos do autor). Com pequenos acréscimos ele declara: “[...] $a$ educação consiste na formação de hábitos de pensar despertos, cuidadosos, meticulosos.” (DEWEY, 1979a, p. 86, itálicos do autor). Que entende Dewey por reflexão?

O pensamento reflexivo consiste, para Dewey numa: “[...] espécie de pensamento que consiste em examinar mentalmente o assunto e dar-lhe consideração séria e consecutiva.” (DEWEY, 1979a, p. 13) Ele continua o argumento dizendo que pensar é uma questão de maneira de empregar 
numerosos objetos observados e sugeridos, maneira de conjugá-los e manejálos. Reflexão significa consequência (não é simples sequência), implica ordem, é consecutiva: “[...] cada ideia engendra a seguinte como seu efeito natural e, ao mesmo tempo, apoia-se na antecessora ou a esta se refere." (DEWEY, 1979a, p. 14). As partes, anéis ou termos se derivam e sustentam, transformam-se numa série, numa cadeia, constituindo assim, “[...] unidades definidas, ligadas entre si de tal arte que o resultado é um movimento continuado para um fim comum." (DEWEY, 1979a, p. 14) Dewey insere nesta sua concepção de pensar reflexivo a necessária relação com o agir: "O pensamento ou reflexão, [...] é o discernimento da relação entre aquilo que tentamos fazer e o que sucede em consequência. Sem algum elemento intelectual não é possível nenhuma experiência significativa" (DEWEY, 1979b, p. 159).

Segundo Dewey: “A reflexão não nasce simplesmente da situação, mas remonta a esta. Sua finalidade e resultado são decididos pela situação de que surgiu." (DEWEY, 1979a, p. 104, grifos do autor). A reflexão, como parte do curso dos acontecimentos de uma experiência, está destinada a influir no resultado destes: "A reflexão subentende também interesse pelo desenlace - uma certa identificação simpática de nosso próprio destino, pelo menos imaginativamente, com o resultado do curso dos acontecimentos." (DEWEY, 1979b, p. 161).

Dewey deixa claro que há modalidades de pensamento que não são reflexivas. Há uma diversidade de atividades mentais que não são reflexivas como, por exemplo, o pensamento empírico ou "pensar popular", o método de tentativa e erro, ou mesmo o que chama de corrente da consciência. Estes processos são constituídos pelas inferências comuns, associações livres das ideias ou memórias. Diferentemente, no processo reflexivo: “[...] pensar é o esforço intencional para descobrir as relações específicas entre uma coisa que fazemos e a consequência que resulta de modo a haver continuidade entre ambas" (DEWEY, 1979b, p. 159, grifos do autor).

Outra característica do pensamento reflexivo, esboçada na introdução da obra Como pensamos, consiste em ser ele uma sucessão 
controlada de representações mentais de algo não realmente presente. Ele se aplica a coisas não diretamente percebidas pelos sentidos. No pensamento reflexivo, afirma Dewey, transparece um "traço inventivo", e é "[...] algo distinto do fiel registro de observação" (DEWEY, 1979a, p. 15). Ele distingue dois aspectos do pensamento reflexivo: a um chama de pensamento ou ideia, que é a representação mental de algo não realmente presente; ao outro, que é o pensar propriamente como uma sucessão de tais representações num fio contínuo e coerente, em unidades definidas e ligadas de tal maneira que resulta num movimento continuado para um fim. Utiliza também as expressões correnteza, fluxo que se transforma numa série, numa cadeia. Ele aspira atingir uma conclusão, um alvo, “[...] que determina uma tarefa controladora da sequência de ideias" (DEWEY, 1979a, p. 16). O que o pensamento reflexivo faz "[...] é exame ativo, prolongado e cuidadoso da crença ou conhecimento hipotético, efetuado à luz dos argumentos que a apoiam e das conclusões a que chega" (DEWEY, 1979a, p. 18). Exige esforço consciente e voluntário para extrair os significados da experiência: "Pensar se equivale, assim, a patentear, a tornar explícito o elemento inteligível de nossa experiência. Tornar possível o proceder-se tendo um fim em vista. É a condição para termos objetivos" (DEWEY, 1979b, p. 159). Fica evidente que pensamento reflexivo é exame de conhecimento ou crença como possibilidade de criação de hipóteses que concorrem para a solução do problema que surge da experiência numa situação de espaço e tempo bem situada.

Nesta perspectiva, a prática de exame de crenças implica em tomálas como hipotéticas e submetê-las ao crivo da reflexão averiguando sua constituição histórico-social, seus preconceitos e a possibilidade delas contribuírem para a solução dos problemas da experiência presente. A prática reflexiva é criadora de novos significados como antecipadora das possíveis consequências do agir diante de determinada situação problemática. A possibilidade de ter acesso imaginativamente pelo processo reflexivo às possíveis consequências cria as condições para a escolha, sendo, portanto um processo inerente à prática de liberdade. Assim, o autor vai definir a educação 
como a contínua reconstrução das crenças que orientam a experiência humana, contrapondo-se à prática da educação tradicional de transmissão de saberes como verdades absolutas. A prática reflexiva como reconstrução criativa deve orientar o agir pedagógico em diversas dimensões das quais podemos destacar as seguintes: o âmbito da moral e da ética, da epistemologia ou lógica do pensar, da política e da estética. A prática reflexiva é concebida pelo autor como um hábito que deve habitar e habilitar a experiência, rompendo com a rotina e fundamentalismo e compromissada com uma postura falibilista diante da prática democrática. Neste sentido, a prática reflexiva deve ser entendida como uma prática social, ativa, contínua, crítica e autônoma uma vez que o agir tem consequências que atingem o outro no presente e no futuro. A prática reflexiva implica compreender que a formação consiste num processo contínuo, portanto o professor está em contínua formação, e pode fazer deste processo também fonte de reflexão e aprendizado na medida em que a problematiza.

Educação é desenvolvimento da capacidade de pensar reflexivo como método de aprender através de uma experiência:

Pensar é o método de se aprender inteligentemente, de aprender aquilo que utiliza e recompensa o espírito. Nós falamos, com bastante propriedade, em métodos de pensar, mas o importante a termos em mente, a este respeito, é que pensar é método, o método da experiência inteligente em seu curso. (DEWEY, 1979b, p. 168-169)

Como Dewey desenvolve a concepção de pensar reflexivo? Dewey desenvolveu os traços mais gerais ou característicos do método de adquirir conhecimentos reflexivamente, ou seja, através da experiência de pensar os problemas que são colocados pela vida.

Dewey indica três forças do pensar que precisam ser cultivadas para a criação do hábito de pensamento reflexivo: curiosidade, sugestão e ordem. Assim, a educação do pensamento depende da criação de condições ${ }^{2}$ para que

\footnotetext{
${ }^{2}$ Dewey reforça e amplia essa ideia em Democracia e educação: "O único caminho direto para aperfeiçoamento duradouro dos métodos de ensinar e aprender consiste em centralizá-
}

Filosofia e Educação [RFE] - Volume 9, Número 2 - Campinas, SP Junho-Setembro de 2017 - ISSN 1984-9605 - p. 48-70 
as "forças" vitais do pensamento - as forças ou tendências presentes em todas as pessoas normais, como enfatiza o autor - possam ser exercitadas e que são básicas para a formação de hábitos de pensamento reflexivo:

[...] o problema de método na formação de hábitos de pensamento reflexivo é o problema de estabelecer condições que despertem a curiosidade; de preparar, nas coisas experimentadas, as conexões que, ulteriormente, promovam o fluxo das sugestões, criem problemas e propósitos que favoreçam a consecutividade na sucessão de ideias. (DEWEY, 1979a, p. 63, itálicos do autor).

Colocados estes pressupostos, podemos adentrar na experiência de aprendizagem reflexiva, identificando o autor chama de "[...] traços indispensáveis do pensamento reflexivo." (DEWEY, 1979a, p. 120) Uma situação de experiência, em que a atividade seja contínua e de interesse do aluno, é o estágio inicial do pensar e da educação. Mas há que se resguardar o sentido da ideia de experiência com a qual Dewey trabalha: ação / fazer reação - significação. Romper este processo levou as teorias filosóficas e educacionais a conceber a possibilidade de cultivar o pensamento separado da experiência, e esta como algo presumido na vida do aluno. Dewey insiste nesse ponto: “[...] é indispensável uma situação empírica atual para a fase inicial do ato de pensar.” (DEWEY, 1979b, p. 168-153) Esta situação deve ser aquela que na própria vida do estudante é motivo de reflexão. Então o aluno terá "[...] alguma coisa para fazer e não alguma coisa para aprender." (DEWEY, 1979b, p.169-154) Este fazer exige reflexão, perceber relações, trabalhar com as observações e raciocínio possibilitando a aprendizagem. Dewey descreve o desenvolvimento do processo reflexivo em cinco passos:

Isto é o que se refere aos aspectos gerais de uma experiência reflexiva. São eles: 1) perplexidade, confusão e dúvida, devidas ao fato de que a pessoa está envolvida em uma situação incompleta cujo caráter não

los nas condições que estimulam, promovem e põem em prova a reflexão e o pensamento." (DEWEY, 1979B, p. 167) 
ficou plenamente determinado ainda; 2) uma previsão conjetural - uma tentativa de interpretação dos elementos dados, atribuindo-lhes uma tendência para produzir certas consequências; 3) um cuidadoso exame (observação, inspeção, exploração, análise) de todas as considerações possíveis que definam e esclareçam o problema a resolver; 4) a consequente elaboração de uma tentativa de hipótese para torná-lo mais preciso e mais coerente, harmonizando-se com uma série maior de circunstâncias; 5) tomar como base a hipótese concebida, para o plano de ação aplicável ao existente estado de coisas; fazer alguma coisa para produzir o resultado previsto e por esse modo pôr em prova a hipótese. (DEWEY, 1979, p. 164-165)

Com isso, Dewey estabelece um ponto central em sua teoria educacional: o estudo, o aprendizado através da experiência reflexiva é descoberta e esta é um processo de fazer inferências entre as significações acumuladas de experiências passadas diante de problemas atuais que permitem prever as consequências da ação e não armazenamento de conhecimentos de experiências alheias ideadas como verdadeiras. Despejar conhecimentos na mente da criança, como se houvesse um aprendizado de ideias diretamente, é trabalho perdido: “[...] nenhum pensamento ou ideia pode ser transferido como ideia de uma pessoa para outra" (DEWEY, 1979b, p. 175). Isto porque, explica Dewey, a ideia que é comunicada constitui um fato para quem ouve permeado de inúmeros outros significados. Esta ideia não é algo que passou pela experiência da criança, por isso não tem este caráter vital a não ser como uma lição ou uma exigência para passar num exame:

A comunicação pode servir de estímulo para a outra pessoa compreender a questão e conceber uma ideia semelhante, ou pode abafar seu interesse intelectual e aniquilar seu incipiente esforço para pensar. Mas aquilo que ela aprende diretamente não pode ser uma ideia. (DEWEY, 1979b, p. 175) 
Os próprios alunos tomam estas supostas ideias como conhecimentos inúteis e inertes. Dewey levanta duas consequências nefastas para a vida do estudante:

A experiência ordinária dos estudantes não adquire o enriquecimento que poderia ter; não é fecundada pelos estudos escolares. E as atitudes advindas, de costumarem-se a isso e de absorver material semicompreendido e semidigerido, enfraquecem o vigor e a eficiência mentais. (DEWEY, 1979b, p. 177)

Isto significa que a criança está imersa numa experiência deseducativa, aquela que não permite crescimento, mas paralisia de suas capacidades. Em contraposição, a posse de uma ideia vem na medida em que a pessoa trabalha reflexivamente com um problema como causa sua, vital, e que lhe cobra uma resposta. Os pais e professores podem oferecer condições que estimulem o pensamento e cooperar com a experiência conjunta, mas não podem assumir e resolver o problema por outro. Somente nesta condição haverá aprendizado. $\mathrm{O}$ que se pode fazer é proporcionar situações significativas na qual a atividade do aprendiz origine, reforce e prove as ideias, significações, relações percebidas. Neste sentido, Dewey destaca o papel ativo do professor:

Isto não quer dizer que o docente fique de lado, como simples espectador, pois o oposto de fornecer ideias já feitas e matéria já preparada, e de ouvir se o aluno reproduz exatamente o ensinado, não é inércia e sim a participação na atividade. Em tal atividade compartida, o professor é um aluno e o aluno é, sem saber, um professor - e, tudo bem considerado, melhor será que, tanto o que dá como o que recebe a instrução tenha menos consciência possível de seu papel. (DEWEY, 1979b, p. 176)

Como vimos, pensar reflexivo não se confunde com a mera expressão de uma opinião ou pergunta posta para outro responder. Ele se caracteriza como um processo em que a reflexão em torno de um problema 
persegue fases que dão vida aos conhecimentos adquiridos, aperfeiçoa a percepção, valoriza o trabalho da imaginação na criação de conjecturas, pontos de vista ou métodos para lidar com uma situação e, assim, apresenta possibilidades de um agir pautado por possíveis consequência previamente pensadas. Não é só trabalho mental. Ele se completa quando os resultados são postos em ação para se firmar ou não como solução. Diz Dewey: "Faltamlhes precisão e certeza enquanto não forem aplicados nessas situações. Somente a aplicação os põe em prova e somente essa comprovação lhe confere pleno significado e o sentido de sua realidade." (DEWEY, 1979b, p. 177). Esta fase é de capital importância para que os conhecimentos ainda na forma de conjecturas não sejam elevados à categoria de verdades, num reino mental constituído por si mesmo.

Assim, para se atingir esta etapa do pensamento reflexivo é necessário equipar as escolas para desenvolver inteligentemente a experiência diária pela reflexão:

Nos lugares em que as escolas são providas de laboratórios, oficinas e jardins, e em que se usam livremente dramatizações, brinquedos e jogos, existem oportunidades para se reproduzirem as situações da vida, e para adquirir e aplicar informações e ideias na realização de experiências progressivas. As ideias não ficam segregadas, a formarem uma ilha isolada. Elas animam e enriquecem o curso da vida comum. Os conhecimentos vitalizam-se com o ser postos em ação, com o exercerem a sua função na direção das atividades. (DEWEY, 1979b, p. 178).

Dewey defende que as escolas sejam aparelhadas com recursos que criem o ambiente para a aprendizagem, "[...] de modo a proporcionar aos estudantes ensejo para adquirirem e provarem as ideias e os conhecimentos em trabalhos ativos reproduzindo (typifying) importantes situações sociais" (DEWEY, 1979b, p. 179).

Mesmo numa escola não adequadamente equipada, os professores podem utilizar métodos mais adequados de interconexão da experiência 
extra-escolar com a matéria escolar, fazendo com que o estudante estabeleça os respectivos contatos e influências mútuas:

Mas este estado de coisas não serve de desculpa aos professores para cruzarem os braços e persistirem em métodos que afastam, isolam e tornam inúteis os conhecimentos escolares. Cada lição de dada matéria fornece ocasião de estabelecer associações estreitas entre o assunto tratado e as mais amplas e diretas experiências da vida quotidiana. (DEWEY, 1979b, p.179)

Disso decorre a necessidade de uma formação contínua do professor para rever seus métodos tendo como preocupação central trabalhar as experiências de vida dos alunos como a fonte mais genuína de onde emergem os problemas a serem tratados com o rigor de uma investigação inteligente ou reflexiva.

Dewey destaca dois problemas que o professor deverá enfrentar na formação de hábitos de pensamento. Um desses problemas consiste no estudo dos traços e hábitos individuais dos seus alunos e ao entendimento do pensar lógico (o conteúdo organizado de acordo com a lógica do especialista na matéria) e do psicológico (a mente ativa do aluno) como conexos e não opostos. Ele afirma:

Qualquer professor, sensível às maneiras por que funciona o pensamento na experiência natural da criança normal, não terá dificuldade em evitar a identificação do lógico como uma organização já pronta da matéria, bem como a noção de que o modo de esquivar-se a esse erro é dasatender às considerações lógicas. (DEWEY, 1979a, p. 90)

Dewey alerta que o professor deve reconhecer que a disposição lógica estritamente do ponto de vista da matéria não é a única disposição possível; ela representa as conclusões concentradas - definições, divisões, classificações - de um espírito experimentado, exercitado. No caso da 
criança, esse processo se dará dentro do grau de desenvolvimento lógico de sua mente. Adverte Dewey: “[...] a única maneira pela qual pode alguém conseguir capacidade em fazer definições exatas, classificações perspicazes e generalizações compreensivas é dentro de seu nível presente, pensar com atenção e cuidado" (DEWEY, 1979a, p. 80, itálico do autor). Neste sentido, Dewey insiste na importância do diálogo na experiência de aprendizagem de forma que o professor tem como saber de onde partir e com o que trabalhar. Cabe, também, ao professor exigir do aluno alguma espécie de organização intelectual, se ele deseja impedir a formação de hábitos mentais de indeterminação, desordem, incoerência. Entretanto, o professor não pode exigir do principiante a mesma organização que satisfaz ao perito, ou, pior ainda, que ele dê continuidade onde para o perito, porque a mente ainda imatura está em processo de aquisição da habilidade intelectual já conseguida pelo perito. O papel de professor consiste em levar a operar o pensamento: “[...] exigir de si próprio um exame minucioso, uma ordenação consecutiva e uma espécie de sumário e formulação de suas conclusões, junto a uma demonstração das razões em que elas se baseiam" (DEWEY, 1979a, p. 91, itálico do autor).

A aquisição de concepções que as pessoas de experiência madura utilizam numa área de conhecimento não está ainda ao alcance das crianças novas, a menos que se dê crédito ao depósito como valor educacional. Dewey defende que a educação consiste num processo vital de elaboração das ideias sobre o que é experienciado, entendendo que a atividade educativa é uma atividade reflexiva que exige formação de conceitos:

[...] em toda fase de desenvolvimento, cada lição, para ser educativa, deveria conduzir a uma certa dose de conceptualização de impressões e ideias. Sem essa conceptualização ou intelectualização, nada se ganha que possa contribuir para uma melhor compreensão de novas experiências. [...] tal intelectualização é o depósito de uma ideia, definida e geral a um tempo. Educação, em seu aspecto intelectual, e obtenção de uma ideia do que é experimentado são expressões sinônimas. (DEWEY, 1979a, p. 155/6, itálicos do autor) 
O outro problema que o professor deverá enfrentar reflexivamente é o estudo das condições escolares mais amplas que atuam sobre a criação de atitudes éticas permanentes ou traços de caráter, dos quais ele destaca o espírito aberto, o devotamento de coração e a responsabilidade. Estas condições escolares amplas que interferem no substrato do pensamento, ou seja, na curiosidade, sugestão e atividade ordenada da criança. Isto quer dizer que a criança está também sujeita à influência que, inconscientemente, recebe do ambiente em sua totalidade. Dewey destaca a importância de se considerar a organização mental da criança e as condições escolares na escolha de métodos:

Ao professor que estuda inteligentemente as operações mentais individuais e os efeitos das condições escolares sobre essas operações, pode-se confiar inteiramente a escolha de métodos de instrução, em seu sentido mais restrito e mais técnico - os mais bem adaptados à obtenção de resultados em matérias particulares, como leitura, geografia, álgebra. (DEWEY, 1979a, p. 64)

A atenção do professor deve estar voltada tanto para os aspectos específicos que influem sobre a aprendizagem de um conteúdo imediato como para as condições mais gerais que interferem no processo de formar hábitos, atitudes e interesses subjacentes e permanentes.

Dewey se contrapõe à atividade escolar que centrada na rotina, na imposição, ou em mecanismos convencionais. Ele defende o planejamento do trabalho educativo como um "trabalho inteligente e consecutivo" em relação às atividades, de acordo com os seguintes fatores: em primeiro lugar está, como foi dito, o interesse, o uso das emoções e desejos, que canalize as energias de maneira significativa para o indivíduo. Em segundo lugar, que os objetos ou ações sejam aproveitados pelos seus valores intrínsecos, ou seja, como "instrumentos de formação de hábitos intelectuais vivos, persistentes, eficientes." O terceiro fator imprescindível no planejamento das atividades é a: 
[...] apresentação de problemas típicos que devam ser resolvidos por reflexão e experimentação pessoal e pela aquisição de conteúdos definidos de conhecimentos capazes de levar, mais tarde, a noções científicas mais especializadas. [...] uma familiaridade com métodos de investigação e prova experimental. (DEWEY, 1979a, p. 214)

O quarto fator é a necessidade de prolongamento dos projetos, a fim de que se consiga sua adequada execução com continuidade, consecutividade e cumulatividade, em relação aos passos e campos por onde se desenvolve a experiência reflexiva.

Terminamos nossas reflexões trazendo a lúcida posição do professor Dewey sobre a missão do próprio professor como um mestre:

O mestre tem a missão não apenas de educar os indivíduos, mas de formar a verdadeira vida social. Todo mestre deveria compreender a dignidade de sua profissão; a de ser um servidor social destinado a manter a verdadeira ordem social e a assegurar o desenvolvimento social acertado. Desse modo, o mestre é sempre o profeta do Deus verdadeiro e o introdutor no verdadeiro reino de Deus. (DEWEY, 1940, p. 370).

Dewey defende uma função bem clara para o professor no processo pedagógico, definida da seguinte forma: “[...] o professor é o líder intelectual de um grupo social: líder, não em virtude de um cargo oficial, mas de seu mais largo e mais profundo acervo de conhecimentos, de sua experiência amadurecida" (DEWEY, 1979a, p. 270).

\section{Considerações finais}

Procuramos explorar nesse artigo alguns pontos importante da teoria filosófico educacional de Dewey acerca da prática reflexiva como princípio 
educativo e, neste sentido, princípio formador para o professor. Resgatamos alguns aspectos.

A formação do professor reflexivo se dá num processo reflexivo. Além da formação teórica e científica que lhe proporciona uma inteligência lógica é necessário também desenvolver a excelência de sua arte em valores como simpatia, criatividade, interesse pelo crescimento dos alunos, dedicação à causa e objetivos sociais.

Concordamos com Teixeira (2000. p. 61) no que diz: "Educar é crescer" e acrescenta: "O critério central há de ser o de transformar a escola em um lugar onde a criança cresce em inteligência, em visão e em comando sobre a vida. (TEIXEIRA, 2000, p. 74).

Concordamos com Zeichner: se por um lado nem todo ensino é reflexivo, por outro lado, o professor que não questiona e examina os objetivos, valores e pressupostos que guiam seu trabalho e não examinam o contexto no qual eles ensinam, não estão engajados em um bom ensino reflexivo. Ensino reflexivo implica em questionamento crítico sobre os fins, meios e contextos de ensino. Ligado a esta perspectiva: "Nós permanecemos firmes em nossa crença que bom ensino reflexivo é tanto democrático quanto autocrítico." (ZEICHNER, 1996, p. 77).

A máxima deweyna de traduzida como "aprender fazendo" interpretamos como "aprender agindo". É na ação que a reflexividade que permite a aprendizagem quando aquela se transforma em conhecimento. Por isso, o processo mesmo de pensar deve ser continuamente posto em suspensão. Originalmente o sentido deste aprender é aprender a pensar. Pensar é exame de conhecimento e crença e também desenvolvimento da sensibilidade na percepção dos problemas. Tais conhecimentos e problemas circunscrevem-se numa esfera social e histórica. As situações problemáticas são contextuais. Trata-se da inseparabilidade do movimento necessário do processo: agir é pensar e pensar é um agir. Aprender com esforço deliberado, desenvolvendo as etapas do processo de solução efetiva de um problema, é essencial para o progresso da inteligência. Este processo forma o cabedal de conceitos e habilidades, tornando os indivíduos e a comunidades melhor 
aparelhadas para solucionar novos problemas. Por sua vez, a educação é um processo que dura a vida toda, considerando que a necessidade de solucionar problemas nunca finda.

A escola, como instituição social, tem o papel de oferecer um ambiente mais controlado e simplificado das situações sociais para guiar a experiência inteligente de solucionar problemas imaginativa e praticamente. O desenvolvimento da capacidade de resolver os problemas sociais, com a participação ativa e livre da vida democrática, depende de um ambiente democrático. A democracia necessita de uma educação que capacite as pessoas na solução inteligente de problemas e não na memorização de conteúdos ou verdades fixas.

A vida democrática é uma forma de vida em que a solução inteligente dos problemas comporta as mais vastas oportunidades, constituindo uma forma de educação moral dos seus membros e reguladora de seus ideais. Torna os indivíduos sensíveis aos problemas sociais e proporciona a investigação pública e cooperativa dos bens sociais, avaliando-os, reajustando ou criando. Prepara para o julgamento de valores. A concepção de um valor está submetida ao processo da concepção de qualquer conceito.

A filosofia da democracia ou da experiência comum deve ser uma filosofia da educação. A atividade filosófica opera na zona de conflitos e tensões sociais e culturais. A unidade encontra-se na continua reconstrução ou criação dos conceitos, a partir do pluralismo das experiências e da variedade de crenças.

Podemos relacionar alguns elementos importantes para compreende experiência de professor reflexivo a partir da obra de Dewey:

O agir filosófico está comprometido com a atividade de pensar os problemas humanos, contextualizados com criticidade, generalização, totalidade, criatividade.

O pensar reflexivo como princípio da função humana como fonte mais genuína de criação dos sentidos orientadores da vida, por isso tem caráter subjetivo, público e ético. Refletir é investiga, procedimento guiado com método lógico, coerência, consequência, autocorretividade. 
O agir é político na medida que a relação teoria e prática tornam possível a liberdade e a democracia. A reflexão não pode estar atividade exclusivamente na sala de aula, mas no contexto micro e macro em que o ensino e a escola estão inseridos.

O agir é ético pois reflete sobre os valores da conduta e acompanha o crescimento da experiência pessoal e social. Neste sentido, o agir é simpático e empático com a vida coletiva, com a experiência da criança e da humanidade, com a inteligência, e faz de seu trabalho um "amor à sabedoria".

Estas características do agir fazem do professor um servidor social que entende a educação como fator de transformação das estruturas na direção da justiça e solidariedade.

\section{Referências}

AMARAL, Maria N. C. Pacheco. 1990. Dewey: Filosofia e experiência democrática. São Paulo: Perspectiva/EDUSP.

Dewey: jogo e filosofia da experiência democrática. In: KISHIMOTO, T. M. (org.) O brincar e suas teorias. São Paulo: Pioneira, 1998. p.79-107.

DEWEY, John. Como pensamos como se relaciona o pensamento reflexivo com o processo educativo: uma reexposição. Trad. Haydée Camargo Campos. 4.ed. São Paulo: Nacional, 1979a. Atualidades pedagógicas; vol. 2. 292 p. Democracia e educação. Trad. Godofredo Rangel e Anísio Teixeira. São Paulo: Nacional, 1979b. Atualidades pedagógicas; vol. 21. 416p. . Education today. Edited and with a foreword by Joseph Ratner. New York: G.P. Putnam's Sons, 1940. 373p. . El Hombre y sus problemas. Buenos Aires: Editorial Paidós, 1952. - Experiência e educação. Trad. Anísio Teixeira. São Paulo: Editora Nacional, 1971.

. From absolutism to experimentalism. In: ADAMS, G.P., MONTAGUE, W.P. Contemporary American philosophy, vol. II. New York: The Macmillan Co., 1930. p. 12-27. . Liberalismo, liberdade e cultura. Trad. Anísio Teixeira. São Paulo: Nacional, 1970. 261p 
Logic. The theory of inquiry. New York: Henry Hold and Company, 1960. $546 \mathrm{p}$.

. Reconstrução em filosofia. Trad. Antônio Pinto de Carvalho. São Paulo: Nacional. 1959a.

. The school and the society. In: Introduction and notes by Martin S. Dworkin.

New York: Columbia University, 1961. p. 33-90.

. Vida e Educação. Trad. Anísio Teixeira. 3.ed. São Paulo: Nacional, $1959 \mathrm{~b}$

DEWEY, John; DEWEY, Evelyn. Schools of to-morrow. New York: E. P. Dutton \& Company, 15. Ed., 1924.

HERBART, Johann Friedrich. Pedagogia geral. Lisboa: Calouste Gulbenkian, 2003.

TEIXEIRA, Anísio. Educação não éprivilégio. Rio de Janeiro: Editora UFRJ, 2007.

ZEICHNER, Kenneth M. LISTON, Daniel P. Reflective teaching. New York: Routledge, 1996. 